\title{
BMJ Open Breastfeeding and behavioural problems: Propensity score matching with a national cohort of infants in Chile
}

\author{
Lisa-Christine Girard, ${ }^{1}$ Chamarrita Farkas ${ }^{2}$
}

To cite: Girard L-C, Farkas C. Breastfeeding and behavioural problems: Propensity score matching with a national cohort of infants in Chile. BMJ Open 2019;9:e025058. doi:10.1136/ bmjopen-2018-025058

- Prepublication history and additional material for this paper are available online. To view these files, please visit the journal online (http://dx.doi org/10.1136/bmjopen-2018025058).

Received 27 June 2018 Revised 14 December 2018 Accepted 17 December 2018

Check for updates

(C) Author(s) (or their employer(s)) 2019. Re-use permitted under CC BY-NC. No commercial re-use. See rights and permissions. Published by BMJ.

${ }^{1}$ School of Health in Social Science, Clinical Psychology, University of Edinburgh,

Edinburgh, UK

${ }^{2}$ Psychology School, Pontificia Universidad Católica de Chile, Santiago, Chile

Correspondence to

Dr Lisa-Christine Girard;

Lisa-Christine.Girard@ed.ac.uk

\section{ABSTRACT}

Importance Potential effects of breast feeding on children's behaviour remains an elusive debate given inherent methodological challenges. Propensity score matching affords benefits by ensuring greater equivalence on observable social and health determinants, helping to reduce bias between groups. Objectives We examined whether the duration of breast feeding had an impact on children's externalising and internalising behaviours.

Study design A cohort study (Encuesta Longitudinal de la Primera Infancia cohort) that included 3037 Chilean families who were enrolled in 2010. Follow-up data was collected in 2012.

Setting General community.

Participants Population-based sample. Eligibility criteria: children born full-term with complete data on matching variables. Matching variables included: healthcare system as a proxy of income, presence of a partner/spouse in the household, maternal age, educational level, IQ, working status, type of work, diagnosis of prenatal depression by a healthcare professional, smoking during pregnancy, delivery type, child sex, weight at birth, incubation following delivery, and child age.

Exposure Duration of breast feeding.

Main outcomes and measures Externalising and internalising problems assessed using the Child Behaviour Checklist.

Results Matched results revealed benefits of any breast feeding, up to 6 months, on emotional reactivity and somatic complaints (mean difference of -1.00 , $95 \% \mathrm{Cl},-1.84$ to -0.16 and $-1.02,95 \% \mathrm{Cl},-1.76$ to -0.28 , respectively). Children breast fed between 7 and 12 months also had reduced scores on emotional reactivity, in addition to attention problems (mean difference of $-0.86,95 \% \mathrm{Cl},-1.66$ to -0.06 and $-0.50,95 \% \mathrm{Cl},-0.93$ to -0.07 , respectively). No benefits were observed for children breast fed 13 months or more.

Conclusion Reduced internalising difficulties and inattention were found in children breast fed up to a year, suggesting that breast feeding may have beneficial impacts on these areas of development. The magnitude of effect was modest. Extended durations of breast feeding did not appear to offer any benefits.
Strengths and limitations of this study

- Use of a quasi-experimental statistical approach to match children with the propensity to be breast fed to those who were not on observable health and social determinates.

- Use of a large Chilean cohort where confounding structure differs from developed countries.

- The inclusion of 14 matching variables including maternal $I Q$, which is almost double the average amount of variables included in similar studies.

- No specific information was collected on full breast feeding in this cohort restricting the study to examining duration only.

- As a result of the inclusion/exclusion criteria, the sample size was reduced from the entire cohort.

\section{INTRODUCTION}

A considerable amount of literature supports numerous medical benefits of breast feeding for children in reducing, for example, the risk of non-specific gastroenteritis, severe lower respiratory tract infections, atopic dermatitis, obesity and high systolic blood pressure. ${ }^{1-3}$ However, the benefits of breast feeding on children's behavioural outcomes are less clear-cut. Differing hypotheses have been put forth regarding potential mechanisms for the perceived associations between breast feeding and behavioural outcomes. For example, it has been suggested that breast feeding may lead to reduced behavioural difficulties as a result of early skin-to-skin contact, when active bonding is present, helping to promote the development of a secure bond between mother and baby. ${ }^{4}$ This may be particularly salient in protecting against the emergence of internalising behaviours as children develop. ${ }^{5}$ On the other hand, associations between breast feeding and behavioural outcomes may be the result of the long-chain polyunsaturated fatty acids (PUFA) ( $\mathrm{n}-3$ and $\mathrm{n}-6$ PUFA) found in breast milk, which arguably 
have an impact on brain development and white growth matter, an area of the brain which is typically underdeveloped in children who display with elevated levels of externalising behaviours. ${ }^{6} 7$ Moreover, deficits in $\mathrm{n}-3$ PUFA, in particular, have been shown to increase the risk of neuronal abnormalities in studies of rats, associated with increased levels of anxiety, depression, aggression, inattention and hyperactivity. ${ }^{8-10}$ While the mechanisms suggested have differing implications regarding pathways of potential effects, it is important to first be able to untangle whether 'effects' exist for children's behavioural outcomes, irrespective of selection and confounding. For example, it may be possible that there is no direct mechanism through which breast feeding is implicated in behavioural outcomes, but rather, associations found may be an artefact of maternal and family-level characteristics.

There has been mixed support for associations between breast feeding and externalising behaviours such as conduct problems and hyperactivity, ${ }^{11-16}$ and internalising behaviours such as anxiety and depression ${ }^{517-19}$ in studies from infancy to adulthood. When associations are observed, a duration of 4 to 6 months or longer appears to be most common. Systematic differences between studies regarding definitions of breast feeding, classification of behaviours, timing of assessment and statistical approaches for handling confounding and selection bias are likely contributing factors accounting for these inconsistencies. For example, self-selection into breast feeding has repeatedly been implicated in studies examining breast feeding and developmental outcomes. In developed countries in particular, research continues to demonstrate characteristics common in mothers who breast feed (eg, lower engagement in high-risk prenatal behaviours, higher education, higher income and older age at child birth), ${ }^{20}{ }^{21}$ which are also associated with behavioural outcomes. If associations between breast feeding and behavioural difficulties are an artefact of maternal or family characteristics, differences in statistical approaches for handling selection bias will have important consequences. Indeed, this is reflected in the literature whereby the greater the number of implicated confounders are controlled, often, the less likely significant associations remain. ${ }^{22}$

On the other hand, using cohorts from developing countries may provide additional insights given the differing confounding structures. ${ }^{23}$ For example, notable differences between developed and developing countries regarding associated maternal characteristics were recently demonstrated in the Lancet series. ${ }^{21}$ More specifically, maternal characteristics common for mothers in developing countries who breast feed, particularly for longer durations, included poverty, lower socio-economic-status and, in some cases, lower maternal education. ${ }^{2425}$ Given this inverse association between socio-economic standing and selection into breast feeding, replication of associations between breast feeding and behavioural problems may offer additional advantages in better understanding potential 'effects'. Currently, there are a lack of studies examining breast feeding and behavioural outcomes using nationally representative cohorts of infants in Chile, which provides such a possibility. While economic growth has been observed, social inequalities in Chile remain high, particularly for women. ${ }^{26}$ Additionally, challenges in examining associations between longer durations of breast feeding on behavioural outcomes due to low prevalence rates in many developed countries is common. In Chile, the duration of breast feeding has been steadily increasing over the past decade and was reported that, in 2014, $63 \%$ of mothers were still exclusively breast feeding when infants were 6 months of age. ${ }^{27}$ Taken together, examining breastfeeding duration and behavioural outcomes with a nationally representative cohort from Chile may offer additional benefits in our understanding.

\section{OBJECTIVES}

To examine breast feeding and children's behavioural outcomes longitudinally using a quasi-experimental statistical technique to reduce observable differences between groups, whereby attempting to address inherent limitations in observational studies. The duration of breast feeding was examined. Moreover, we examined whether in using a Chilean cohort, we could replicate the findings of Girard et $a l^{112}$ regarding reduced hyperactivity for children breast fed, following propensity score matching, in two separate longitudinal Irish cohorts. We extend on this work by also examining internalising behaviours. We hypothesised, in line with previous findings and recommendations of the $\mathrm{WHO},{ }^{28}$ that children who were breast fed for a minimum of 6 months would present with reduced behavioural problems in early childhood.

\section{METHOD}

Participants included families enrolled in the Encuesta Longitudinal de la Primera Infancia cohort (ELPI), recruited in Chile in 2010 and 2012. Families recruited in the second wave (ie, in 2012) were not considered in this study given that child outcomes were not available longitudinally. The cohort was initially recruited to better understand the socio-demographic backgrounds of children and their families alongside their physical, social and emotional development over time. The cohort is representative of children born between January 2006 and August 2009 in urban and rural areas, across all regions of Chile. ${ }^{29}$ A total of 15175 families with children between the ages of seven and 58 months were initially contacted for inclusion. At wave 1, 14161 families were assessed, which was $93.3 \%$ of the targeted sample. However, 487 children did not have information pertaining to their age and were excluded. Inclusion criteria in this study were children aged 7 to 24 months, who had complete data on all confounders at wave 1 , and who were born full term $(n=4375)$. Additionally, mothers who were still 
breast feeding at wave 1 who had breast fed more than 6 , but less than 12 months, were excluded ( $\mathrm{n}=442)$, as it was not possible to identify whether they should be included in the group of children breast fed between 7 and 12 months or in the extended breastfeeding group. This resulted in a possible sample of 3933 children and their families, $50.6 \%$ of whom were boys $(\mathrm{n}=1992)$ at wave 1 . However, missing outcome data (ie, child behaviours) at wave 2 in 2012 resulted in a final sample of 3037. Demographic characteristics of the included children and

Table 1 Family, maternal, infant and medical characteristics: infant cohort between 7 and 24 months

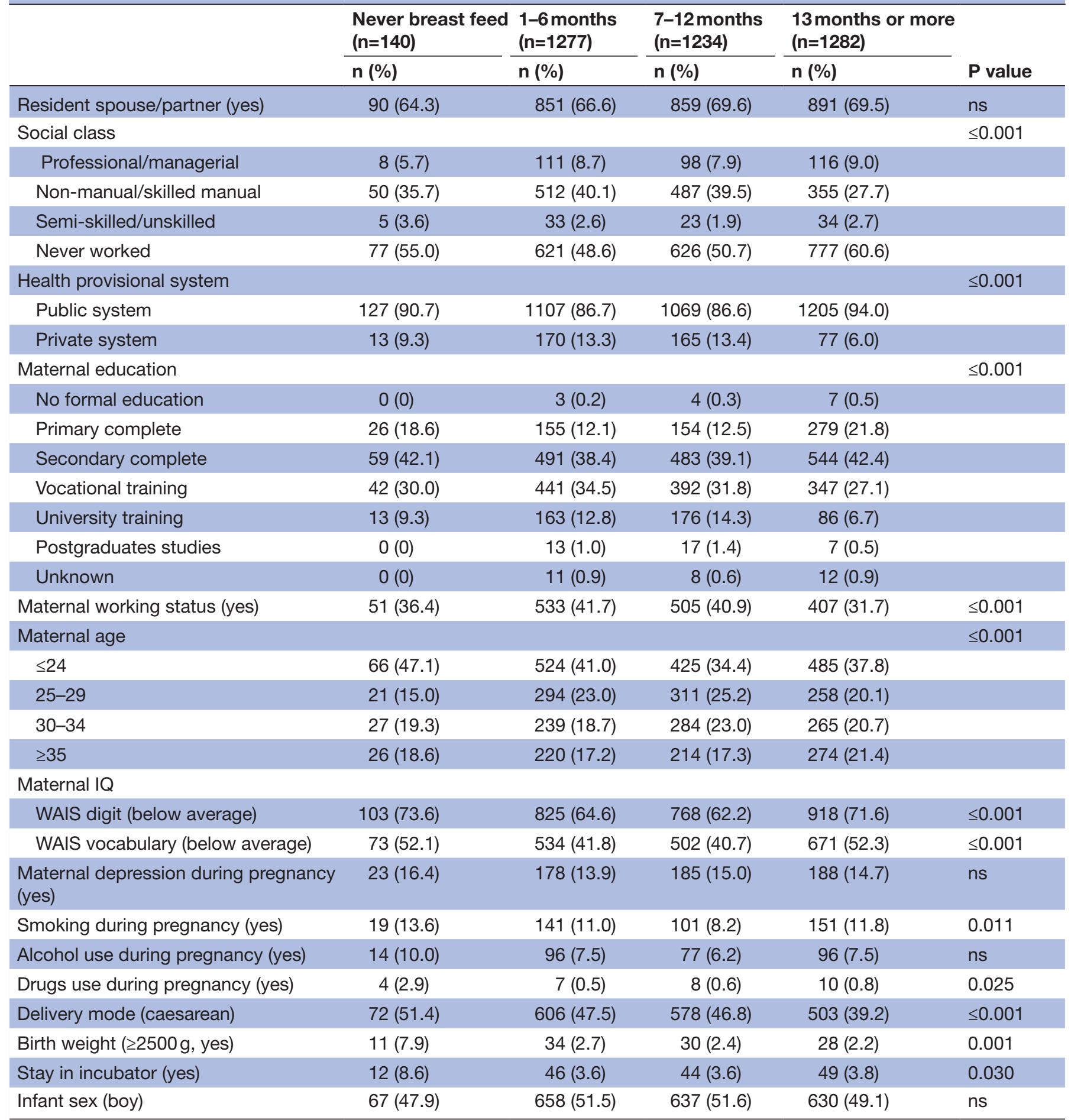

The health provisional system was used as a proxy for the financial status of the family, whereby families in the private system are generally of higher income. Maternal IQ was assessed using both the digit and vocabulary scales of the Wechsler Intelligence Adult Scale (WAIS; Wechsler, 1939). A below average score is defined as a score of 8 or below on the digit and vocabulary scales.

ns, non-significant; WAIS, Weshcler Intelligence Adult Scale. 
Table 2 Bivariate correlations and means (SD) of children's behaviours

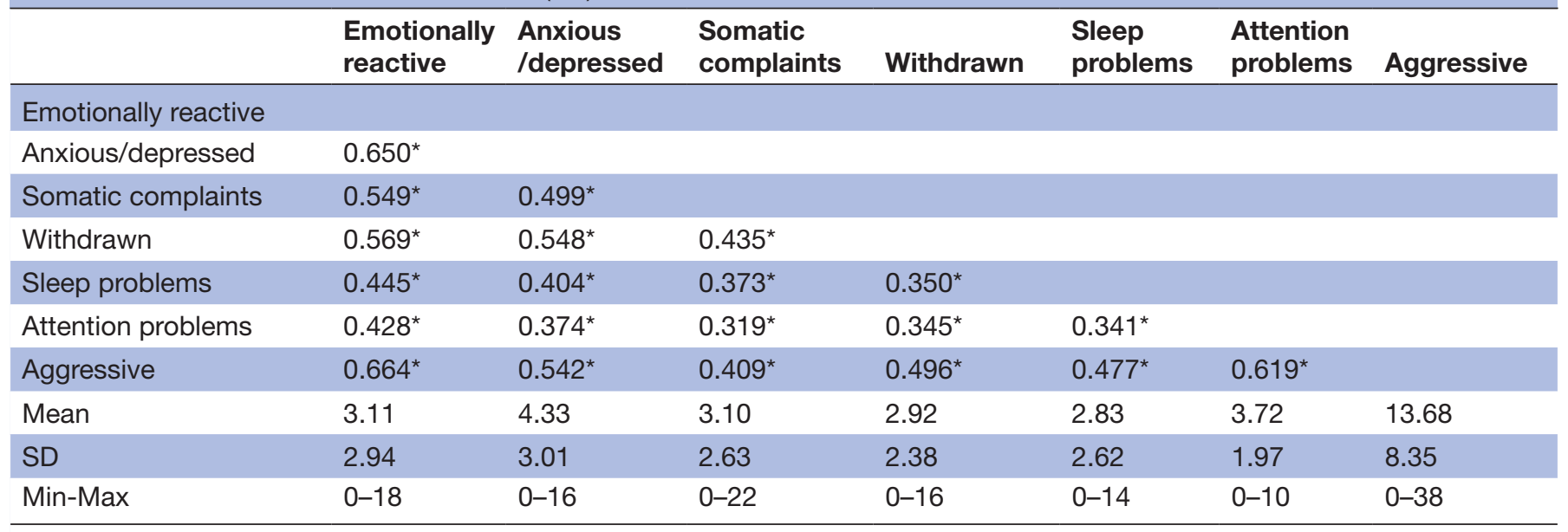

${ }^{*}$ Denotes statistical significance at the 0.01 level.

their families can be found in table 1. A table comparing the entire cohort to those included can be found in the online supplementary material.

Children's behaviours were assessed using the Child Behaviour Checklist 11/2-5 (CBCL). ${ }^{30}$ The CBCL 11/2-5 is a parent report used to identify behavioural problems in children between the ages of one-and-a-half and 5 years. It comprises 99 items divided into subscales. The seven subscales include: emotionally reactive (nine items), anxious/depressed (eight items), somatic complaints (11 items), withdrawn (eight items), sleep problems (seven items), attention problems (five items) and aggression (19 items). Parents rate each individual behavioural item on three-point Likert scale ranging from 0 (not true) to 2 (very true or often true), with higher scores indicative of more problematic behaviour. The CBCL $1 \frac{1 / 2-5}{}$ is available in several languages, including Spanish, and has previously been validated in the literature with Chilean samples. ${ }^{31}$ The CBCL was collected at wave 2 , in 2012, when children were between the ages of 32 and 48 months. The mean and SD values, along with correlations between subscales, are presented in table 2.

Breastfeeding information was collected at wave 1, both retrospectively and prospectively, given the unique sampling approach of recruitment of families with children between the ages of 7 and 58 months. Due to potential recall bias and in an attempt to create more homogeneity within mother's duration of recall, we included only families with children between 7 and 24 months. Mothers were asked two questions: 'was the newborn breast fed by his/ her biological mother?' and 'until what month was the child breast fed by his/her biological mother?' No information was collected regarding full breast feeding in the cohort. Of the sample included, only 140 mothers/caregivers reported that the child had never been breast fed. Based on the WHO recommendations, we grouped children into one of four categories of duration: never breast fed $(\mathrm{n}=140)$, breast fed up to 6 complete months $(\mathrm{n}=1277)$, breast fed between 7 and 12 complete months $(\mathrm{n}=1234)$, and breast fed $\geq 13$ months $(\mathrm{n}=1282)$. Each category of duration was treated as mutually exclusive, dummy coded and compared against children who had never been breast fed.

Numerous confounders and self-selection into breast feeding have been argued to account, at least in part, for previous associations between breast feeding and behavioural outcomes. In the current study we matched groups on 13 of the most commonly identified factors, along with children's age given the variation in this sample. At the family level these included the category of the healthcare system that the family belonged to (public, private) as a proxy of income, and the presence of a partner/spouse in the household (yes/no). To note, the quality of services offered in the private and public healthcare system in Chile differs vastly, with higher quality services offered in the private system, subsequently translating into a high cost of belonging to the private system. Moreover, for those employed, the tier of the healthcare system in which one belongs is directly related to salary, whereby employers pay into the healthcare system on their employees' behalf, which is a calculated monthly percentage deductable, based on individual income earnings. At the maternal level, confounders included maternal age, educational level (no formal education, primary, secondary, vocational training, university training, postgraduate), maternal IQ (a score of 8 or below on the Wechsler Intelligence Adult Scale, digit and vocabulary scales (WAIS)), ${ }^{32}$ working status (yes/no), type of work (professional/managerial, non-manual/ skilled manual, semi-skilled/unskilled, unknown/never worked), diagnosis of depression by a healthcare professional during pregnancy (yes/no), smoking during pregnancy (yes/no) and delivery type (vaginal, caesarean). To note, the WAIS has been adapted in Chile with good reported reliability and validity. ${ }^{334}$ At the child level, four confounders were included, namely, child sex (boy/girl), 
weight at birth ( $\geq 2500 \mathrm{~g}$, yes/no), whether the child was placed in an incubator after delivery (yes/no), and age at first assessment in wave 1.

\section{PATIENT AND PUBLIC INVOLVEMENT}

The development of the research question and outcome measures, along with study design and recruitment to the study, were not directly informed by patients' priorities, experience or preference. Study findings will be disseminated to the Ministry of Labour and Social Welfare, which was responsible for waves 1 and 2, and the Ministry of Social Development, which is currently responsible for wave 3 of the ELPI cohort, ensuring greater likelihood of dissemination to study participants.

\section{STATISTICAL ANALYSIS}

We employed the use of propensity score matching (PSM), a statistical approach which attempts to ensure equivalence between treatment and control groups (ie, breast fed, not breast fed), by matching groups on the most relevant factors, subsequently reducing selection bias and confounding. That is, comparisons are made between children who were breast fed and those who were not based on their measured characteristics and similar propensities for being breast fed. Nearest neighbour 1:1 models, with replacement were used. In nearest neighbour matching, groups are first randomly ordered to reduce possible bias in the matching procedure, with matching then occurring sequentially. To ensure the most optimal matches between pairs on propensity scores, we imposed a caliper of a tenth of a SD. That is, for a match to occur, the propensity score of a child who was breast fed to a child who was not, had to fall within a tenth of a SD of one another. Matching with replacement was necessary given the low rates of children who were never breast fed. While this technique can result in larger amounts of variance, it has been argued to reduce bias by ensuring matches are of better quality. ${ }^{35}$ All children fell within the area of common support, which refers to cases being excluded as a result of not fitting within the specified caliper. See figure 1 for the overlapping support of the distribution of propensity scores. To ensure the overall quality of the matching procedure, balance checks were conducted on individual confounders and the overall models. For individual factors, remaining bias ranged between $0.0 \%$ and $18.8 \%$ (see figure 2) and the overall mean remaining bias for models ranged between $5.5 \%$ and $8.3 \%$. It has been suggested that less than $20 \%$ remaining bias is indicative of good matching, ${ }^{36}$ thus we concluded that our matching was successful. We report on the average treatment effects of those treated (ATT). All analyses were conducted using Stata V.14 software. We use the term significant henceforth to denote statistical significance, using a threshold of $\mathrm{p} \leq 0.05$.

\section{RESULTS}

Comparing children never breast fed to those who were breast fed up to 6 months inclusive, significant differences in favour of those who were breast fed were found on two of the behavioural subscales (ie, emotionally reactive and somatic complaints). These results remained significant following matching whereby children who were breast fed had lower scores on these subscales (ie, a mean difference of $-1.00, d=-0.23$ and $-1.02, d=-0.27$ respectively). Comparing children who were never breast fed to those breast fed between 7 and 12 months inclusive, significant differences were found prior to matching on all subscales with the exception of anxious/depressed and sleep problems. After matching, significant differences remained for emotional reactivity and attention problems only (ie, a mean difference of $-0.86, d=-0.21$ and $-0.50, d=-0.22$, respectively), with reduced difficulties for children who

\section{Breastfed up to 6 Months \\ Breastfed between Breastfed 13 Months or 7 and 12 Months More}

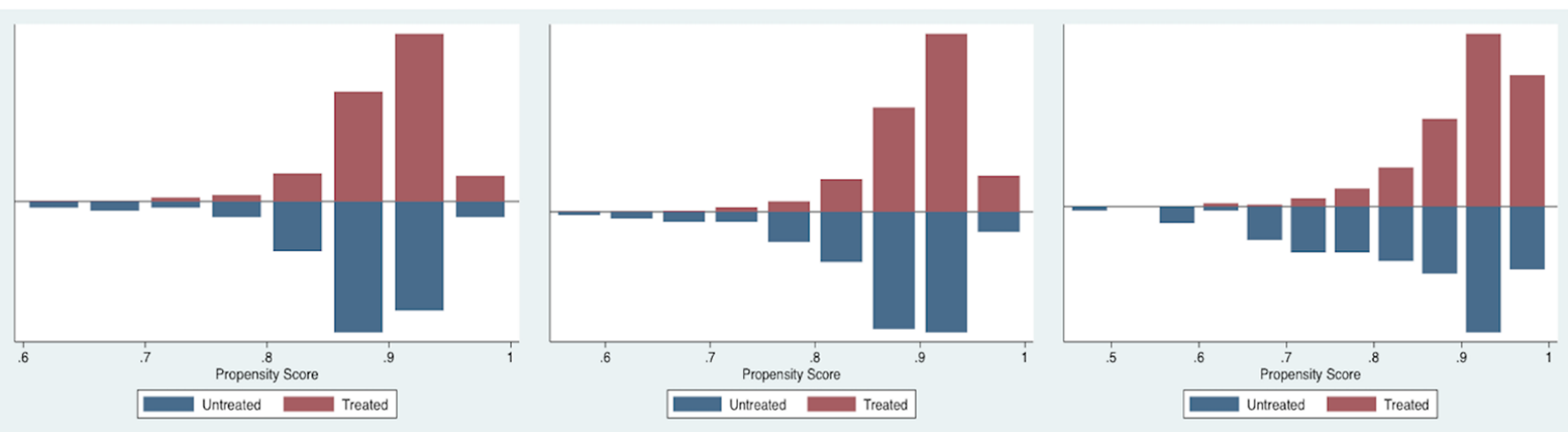

Figure 1 Overlapping Support: Distribution of Propensity Scores. Note: Treated refers to children who were breast fed, untreated refers to children who were not. For being breast fed up to 6 months: $N$ for the treatment group was 949 and 110 for the control group. For being breast fed between 7 and 12 months: $\mathrm{N}$ for the treatment group was 946 and 110 for the control group. For being breast fed 13 months or more: $\mathrm{N}$ for the treatment group was 1006 and 110 for the control group. 


\section{Breastfed up to 6 Months}

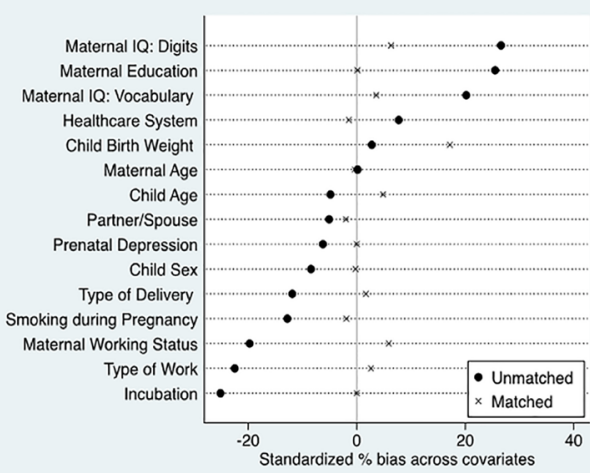

Breastfed between

7 and 12 Months

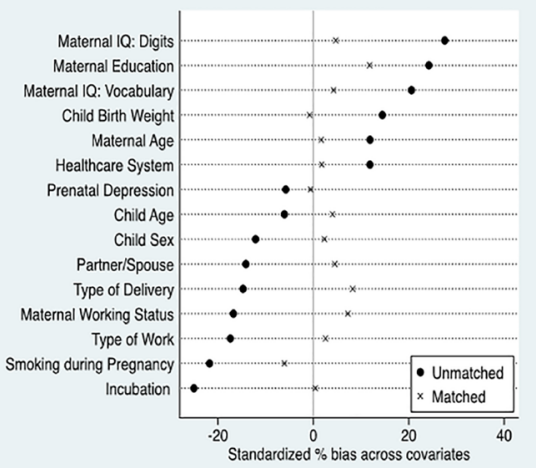

Breastfed 13 Months or More

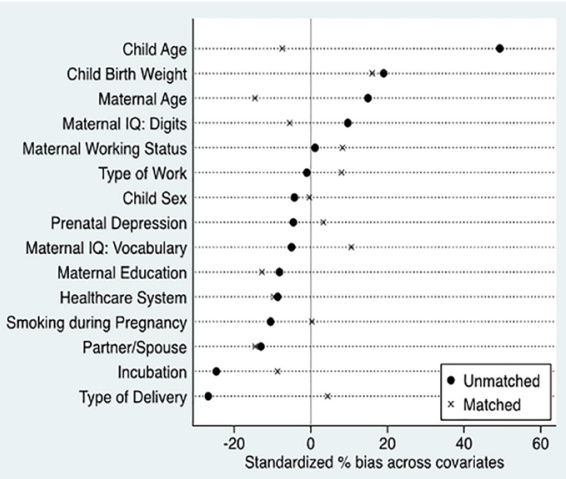

Figure 2 Standardised Differences across Covariates: Pre-Matching and Post-Matching Note: Treated refers to children who were breast fed, untreated refers to children who were not. For being breast fed up to 6 months: $\mathrm{N}$ for the treatment group was 949 and 110 for the control group. For being breast fed between 7 and 12 months: $\mathrm{N}$ for the treatment group was 946 and 110 for the control group. For being breast fed 13 months or more: $\mathrm{N}$ for the treatment group was 1006 and 110 for the control group.

were breast fed. Comparing those never breast fed to the extended group (ie, 13 months or more), pre-matching results were similar to the first model with lower scores on the emotionally reactive and somatic complaints subscales. Post-matching revealed no remaining significant differences between groups. All results can be found in table 3.

\section{DISCUSSION}

While causality remains an ongoing debate, owing to the ethical constraints of conducting randomised controlled trials, our results add to the emerging corpus of literature trying to untangle the 'effects' of breast feeding on behavioural outcomes by using a PSM approach in a Chilean cohort. Given the knowledge of family and maternal characteristics commonly observed of children who are breast fed, the use of matching helps to ensure that differences between groups on these observable characteristics are significantly minimised, so that the propensity to be breast fed across groups is arguably comparable. As a result, only post-matching results are discussed. Due to exclusions, our results have implications only for children who were born full term.

The results suggest that breast feeding may be an effective low-cost early investment for reducing difficulties with emotional reactivity and somatic complaints, in addition to attention problems experienced in early childhood, all of which are indicative of neurodevelopmental difficulties. Duration appears to be an important factor implicated in these associations. For example, results revealed that any breast feeding during the first 6 months, and up to 12 full months, contributed to reductions in children's difficulties with emotional reactivity and somatic complaints up to 4 years of age. In comparison, a minimum of at least 6 full months or more of breast feeding was required for observed benefits related to attention problems at the same age. This latter finding is in line with findings from Girard et al, ${ }^{11}$ who also used PSM in a nationally representative sample of infants from Ireland. The similar results found around 3 years of age, across these two unique cohorts, whilst using PSM, demonstrates favourable support for a direct mechanism between breast feeding and reduced attention problems in early childhood, rather than confounding per se. Worth noting is the link found between inattention/hyperactivity, regulation difficulties and mood disorders, ${ }^{37}$ and their link with deficiencies in arachidonic acid and docosahexaenoic acid. ${ }^{37}$ Given the types of behaviours where reductions for those breast fed are found in this study, and in the context of previous studies, ${ }^{8-10} 3738$ a plausible hypothesis might be that of the nutrients found in breast milk contributing to the growing infant's brain development. More research in this area using well-designed and rigorously sound methodology is first needed before firm conclusions can be drawn.

While our results suggest statistically significant differences in favour of children who were breast fed at least 6 full months (and up until 12 full months), as compared with those who were never breast fed on emotional reactivity, somatic complaints and inattention, the magnitude of effect for each behaviour was found to be small (ie, Cohen's $d=<0.30$ ). The practical and clinical significance of our results is arguably interpretable in the eye of the 'stakeholder'. A small reduction in a child's emotional reactivity, somatic complaints and/or inattention in everyday situations may carry greater importance to a first-time or multiparous mother experiencing high levels of stress and fatigue as a result of limited financial and/ or personal resources. On the other hand, within a clinical context, the effect sizes found may be perceived as carrying less practical importance. 
Table 3 Breast feeding and children's behavioural problems: pre-matching and post-matching results

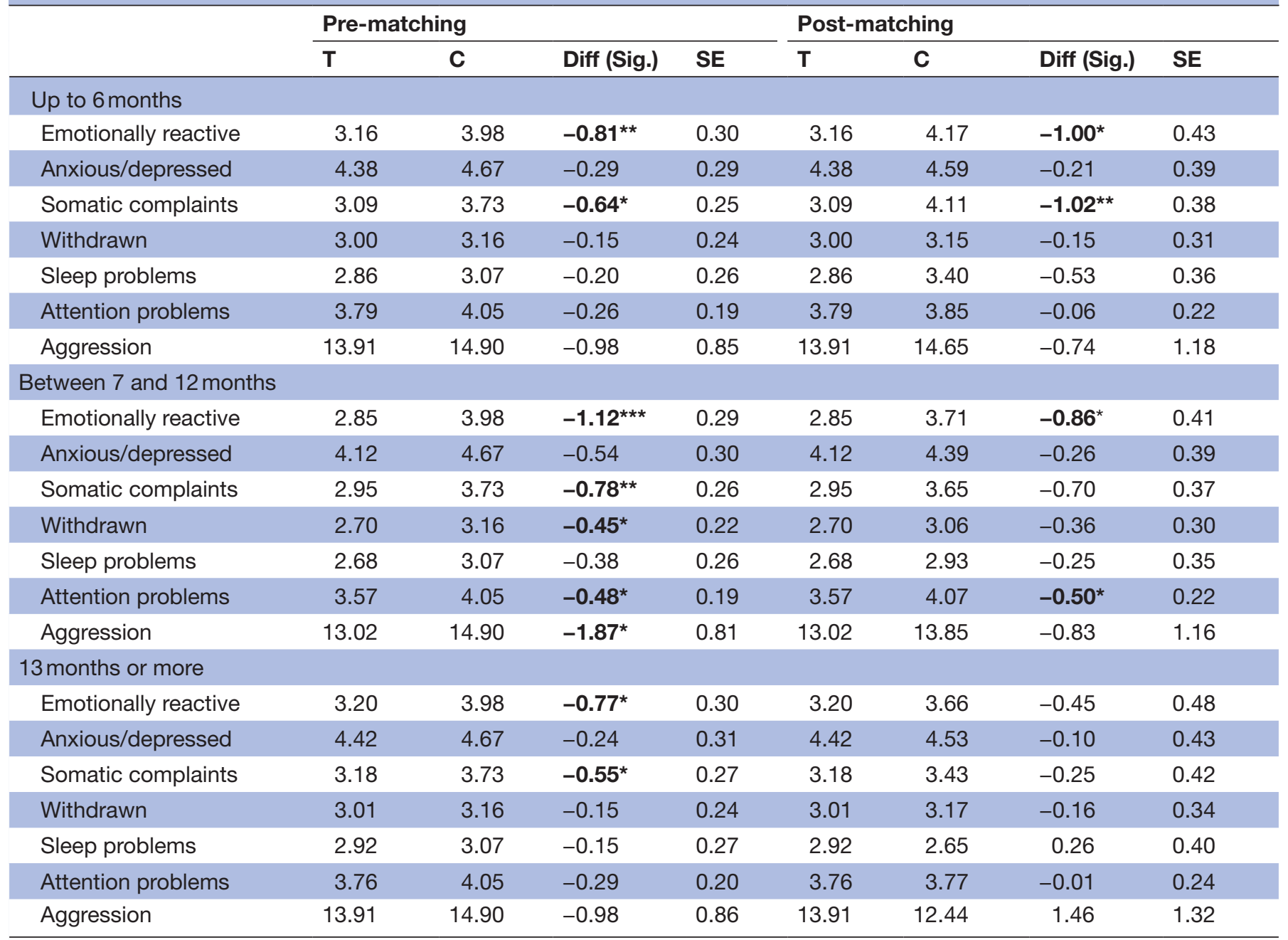

${ }^{* \star *}$ Denotes significance at the $\mathrm{p} \leq 0.001$ level, ${ }^{* \star} \mathrm{At}$ the 0.01 level, ${ }^{\star} A t$ the 0.05 level. All significant differences are highlighted in bold. T denotes 'treatment' (breast fed) and C denotes 'control' (not breast fed). 'Diff' represents the difference in scores between groups. SE refers to the standard errors. For being breast fed up to 6 months: $\mathrm{N}$ for the treatment group was 949 and 110 for the control group. For being breast fed between 7 and 12 months: $\mathrm{N}$ for the treatment group was 946 and 110 for the control group. For being breast fed 13 months or more: $\mathrm{N}$ for the treatment group was 1006 and 110 for the control group.

Conversely, no benefits of extended breast feeding were found on children's internalising or externalising behavioural problems. This may suggest a non-linear doseresponse effect of breast feeding on behaviour, similar to previous findings. ${ }^{12}$ While the recommendations put forth by the WHO for continued partial breast feeding up to 2 years of age or more for the physical health and growth of infants has been suggested, we observed no additional benefits of extended breast feeding on behavioural problems in this sample. These findings do not, however, contradict these recommendations regarding the many afforded medical benefits of extended durations of breast feeding. Of interest and as can be seen in table 1, mothers who breast fed for extended durations in Chile had similar characteristics to mothers who had never breast fed, leading to poorer quality matching. For example, in both the never-breast fed and extended breastfeeding groups, a significantly higher proportion of mothers had never worked, were in the public tier of the health system, had only completed education at the primary level and had below average scores on both the digit and vocabulary scales of the WAIS, factors which when previously controlled, have reduced observed associations between breast feeding and children's cognitive and behavioural development outcomes. While a non-linear dose-response hypothesis is plausible, these findings also likely support what is already known. Maternal characteristics contribute to children's behavioural outcomes and the nutrients alone found in breast milk may be only part of the story. Moreover, it supports the differences in confounding structures of breast feeding in low/ middle-income and high-income countries. ${ }^{21} 23$

Notable strengths of this study include the use of the largest nationally representative cohort of Chilean children to date, where self-selection and confounding structures differ from developed countries, whilst utilising 
PSM, with a large number of matching confounders to reduce differences across groups, of which included maternal IQ. Despite these strengths, notable limitations must be mentioned. While information on necessary supplementation was asked, there was no specific information regarding full breast feeding, limiting our ability to examine its impact. This is an important issue given the differences in feeding experiences and the potential for dilution of effects from breast feeding to behaviour. In the same vein, no information regarding direct breast feeding versus expressed breast milk was collected, information which may help in better understanding pathways of effect. Due to our inclusion/exclusion criteria, the sample size was significantly reduced, with some statistically significant differences between the originally recruited cohort and those included in the current study, indicative of potential selection bias, thus warranting replication. Additionally, despite the benefits afforded by PSM techniques, matching is only possible on observable characteristics. While we were able to include a multitude of health and social confounders, including maternal IQ it remains possible that unobservable characteristics contribute to the associations. Relatedly, the quality of matching for the extended breastfeeding families as compared with the never breastfeeding families was not as successful compared with the matching between the other groups, due to the initial similarities on health and social factors. The included covariates used for matching were theoretically motivated and thus, we kept the integrity of matching variables intact across all models. However, the findings from this model (ie, the extended breastfeeding families) warrants caution in interpretation. Future studies are needed to more carefully evaluate extended breast feeding and potential associations with behavioural outcomes, in the context of differing confounding structure. Finally, shared method variance is a concern given that parent reports were used to collect information on both breastfeeding duration and child behaviours.

Despite these limitations, and in the context of the strengths of this study, we believe these results contribute important findings, namely more support for the potential of 'causal paths'. A comprehensive answer to the question of effects on psychosocial development remains unanswered without the use of RCTs. However, with replication across regions, whilst using more stringent methodological approaches to help in reducing bias inherent in observational studies, promise for better understanding of potential mechanisms is viable.

Contributors Dr L-CG and Professor CF conceptualized the study, carried out the analyses, interpreted the data, drafted the initial manuscript, critically reviewed and revised the manuscript and approved the final manuscript as submitted. Both authors approved the final manuscript as submitted and agree to be accountable for all aspects of the work.

Funding This publication was supported by the College of Arts, Humanities and Social Sciences at the University of Edinburgh.

Competing interests None declared.
Patient consent for publication Not required.

Ethics approval Ethical approval was obtained from the Universidad de Chile, Centro de Microdatos.

Provenance and peer review Not commissioned; externally peer reviewed.

Data sharing statement Data could not be deposited in an open repository; however, researchers wishing to access the data may do so directly by writing a request to the Centro de Microdatos de la Facultad de Economía y Negocios de la Universidad de Chile. Dr. Girard and Prof. Farkas had full access to all the data in the study and take responsibility for the integrity of the data and the accuracy of the data analysis.

Open access This is an open access article distributed in accordance with the Creative Commons Attribution Non Commercial (CC BY-NC 4.0) license, which permits others to distribute, remix, adapt, build upon this work non-commercially, and license their derivative works on different terms, provided the original work is properly cited, appropriate credit is given, any changes made indicated, and the use is non-commercial. See: http://creativecommons.org/licenses/by-nc/4.0/.

\section{REFERENCES}

1. Horta BL, Loret de Mola C, Victora CG. Long-term consequences of breastfeeding on cholesterol, obesity, systolic blood pressure and type 2 diabetes: a systematic review and meta-analysis. Acta Paediatr 2015;104(467):30-7.

2. Ip S, Chung M, Raman G, et al. A summary of the Agency for Healthcare Research and Quality's evidence report on breastfeeding in developed countries. Breastfeed Med 2009;4:S-17-18.

3. Taylor JS, Kacmar JE, Nothnagle M, et al. A systematic review of the literature associating breastfeeding with type 2 diabetes and gestational diabetes. J Am Coll Nutr 2005;24:320-6.

4. Britton JR, Britton HL, Gronwaldt V. Breastfeeding, sensitivity, and attachment. Pediatrics 2006;118:e1436-43.

5. Liu J, Leung P, Yang A. Breastfeeding and active bonding protects against children's internalizing behavior problems. Nutrients 2013;6:76-89.

6. Sarkar S, Craig MC, Catani M, et al. Frontotemporal white-matter microstructural abnormalities in adolescents with conduct disorder: a diffusion tensor imaging study. Psychol Med 2013;43:401-11.

7. Silk TJ, Vance A, Rinehart N, et al. White-matter abnormalities in attention deficit hyperactivity disorder: a diffusion tensor imaging study. Hum Brain Mapp 2009;30:2757-65.

8. DeMar JC, Ma K, Bell JM, et al. One generation of n-3 polyunsaturated fatty acid deprivation increases depression and aggression test scores in rats. J Lipid Res 2006;47:172-80.

9. Fedorova I, Alvheim AR, Hussein N, et al. Deficit in prepulse inhibition in mice caused by dietary n-3 fatty acid deficiency. Behav Neurosci 2009;123:1218-25.

10. Janssen $\mathrm{Cl}$, Kiliaan AJ. Long-chain polyunsaturated fatty acids (LCPUFA) from genesis to senescence: the influence of LCPUFA on neural development, aging, and neurodegeneration. Prog Lipid Res 2014;53:1-17.

11. Girard LC, Doyle O, Tremblay RE. Breastfeeding, cognitive and noncognitive development in early childhood: a population study. Pediatrics 2017;139:e20161848.

12. Girard LC, Doyle O, Tremblay RE. Breastfeeding and externalising problems: a quasi-experimental design with a national cohort. Eur Child Adolesc Psychiatry 2018;27:1-8.

13. Lind JN, Li R, Perrine CG, et al. Breastfeeding and later psychosocial development of children at 6 years of age. Pediatrics 2014;134(Supplement):S36-41.

14. Belfort MB, Rifas-Shiman SL, Kleinman KP, et al. Infant breastfeeding duration and mid-childhood executive function, behavior, and socialemotional development. J Dev Behav Pediatr 2016;37:43-52.

15. Oddy $\mathrm{WH}$, Li J, Robinson $\mathrm{M}$, et al. The long-term effects of breastfeeding on development. Contemporary Pediatrics 2012.

16. Poton WL, Soares ALG, Oliveira ERA, et al. Breastfeeding and behavior disorders among children and adolescents: a systematic review. Rev Saude Publica 2018;52:9.

17. Loret de Mola C, Horta BL, Gonçalves $\mathrm{H}$, et al. Breastfeeding and mental health in adulthood: a birth cohort study in Brazil. J Affect Disord 2016;202:115-9.

18. Fergusson DM, Woodward LJ. Breast feeding and later psychosocial adjustment. Paediatr Perinat Epidemiol 1999;13:144-57.

19. Kwok MK, Leung GM, Schooling CM. Breast feeding and early adolescent behaviour, self-esteem and depression: Hong Kong's 'Children of 1997' birth cohort. Arch Dis Child 2013;98:887-94. 
20. Girard LC, Côté SM, de Lauzon-Guillain B, et al. Factors associated with breastfeeding initiation: a comparison between France and French-Speaking Canada. PLoS One 2016;11:e0166946.

21. Victora CG, Bahl R, Barros AJD, et al. Breastfeeding in the 21st century: epidemiology, mechanisms, and lifelong effect. The Lancet 2016:387:475-90.

22. Walfisch A, Sermer C, Cressman A, et al. Breast milk and cognitive development--the role of confounders: a systematic review. BMJ Open 2013;3:e003259.

23. Brion MJ, Lawlor DA, Matijasevich A, et al. What are the causal effects of breastfeeding on IQ, obesity and blood pressure? Evidence from comparing high-income with middle-income cohorts. Int $J$ Epidemiol 2011;40:670-80.

24. Lutter CK, Chaparro CM, Grummer-Strawn LM. Increases in breastfeeding in Latin America and the Caribbean: an analysis of equity. Health Policy Plan 2011;26:257-65.

25. Pérez-Escamilla R. Breastfeeding and the nutritional transition in the Latin American and Caribbean Region: a success story? Cad Saude Publica 2003;19:S119-27.

26. OCED. OCED economic surveys Chile. 2015. http://www.oecd.org/ eco/surveys/Chile-2015-overview.pdf

27. UNICEF. Estado mundial de la infancia 2014 en cifras [World state of infancy 2014 in numbers]. 2014. https://www.unicef.org/spanish/ sowc2014/numbers/

28. World Health Organization, \& UNICEF. Global strategy for infant and young child feeding. Geneva, Switzerland: World Health Organization Press, 2003.
29. Bravo D. Encuesta Longitudinal de la Primera Infancia: Centro Micro Datos Departamento Economía Universidad de Chile[Links], 2012.

30. Achenbach TM, Rescorla LA. Manual for the ASEBA School-age forms \& profiles. Burlington, VT: University of Vermont, Research Center for Children, Youth, \& Families, 2001.

31. Ivanova MY, Achenbach TM, Rescorla LA, et al. Preschool psychopathology reported by parents in 23 societies: testing the seven-syndrome model of the child behavior checklist for ages 1.5-5 J Am Acad Child Adolesc Psychiatry 2010;49:1215-24.

32. Wechsler D. The measurement of adult intelligence. Baltimore, MD: William and Wilkins, 1939.

33. Berdicewski O, Herreros R. Normas de adaptación WAIS a Chile (Doctoral dissertation, Tesis de Grado no publicada). Santiago, Chile: Universidad de Chile, 1960.

34. Hermosilla M. La Escala de Inteligencia de Wechsler para adultos Wechsler intelligence scale for adults] (unpublished manuscript). Santiago, Chile: Escuela de Psicología, Pontificia Universidad Católica de Chile, 1982

35. Caliendo M, Kopeinig S. Some practical guidance for the implementation of propensity score matching. J Econ Surv 2008;22:31-72.

36. Rosenbaum PR, Rubin DB. The bias due to incomplete matching. Biometrics 1985;41:103-16.

37. Hirshfeld-Becker DR, Biederman J, Faraone SV, et al. Temperamental correlates of disruptive behavior disorders in young children: preliminary findings. Biol Psychiatry 2002;51:563-74.

38. Richardson AJ. Omega-3 fatty acids in ADHD and related neurodevelopmental disorders. Int Rev Psychiatry 2006;18:155-72. 